\section{THE IMPACT OF COVID-19 PANDEMIC IN HIGHER EDUCATION ON TEACHERS AND STUDENTS - A PARALLEL STUDY}

KEY WORDS: Covid-19, Pandemic, Offline, Online, Education, Digital.

Jasmine. $A^{*}$

Assistant Professor, Department Of Visual Communication, Holy Cross College, Tiruchirappalli, Bharathidasan University. ${ }^{*}$ Corresponding Author

COVID-19 has struck our education system like a lightning bolt and shaken it to its core. The pandemic that has shuttered economies around the world has also battered education systems in developing and developed countries. The impact has been dramatic and transformative as educators scramble to put in place workable short-term solutions for remote teaching and learning, particularly in emerging markets, where students and schools face additional challenges related to financing and available infrastructure. Each and every institution are facing unique challenges. The COVID 19 Pandemic has imposed pressures to all sectors of the country and the education sector has also been imposed for the paradigm shift from traditional physical classroom education methodology to the Online classes. Lecturers are still struggling to maintain the same depth of engagement with students that they could have in a classroom setting. Just as the First Industrial Revolution forged today's system of education, we can expect a different kind of educational model to emerge from COVID-19. This paper deals about the teacher's adaptability to new methods of teaching the students in online classes, through videoconference like zoom meet, google meet etc.... and the challenges that they face. Also, this paper presents about the students and their financial difficulty and family support to connect themselves in online for their education and the obstacle they face to move from face to face learning to offline modem.

\section{INTRODUCTION}

\section{Paradigm Shift in India's Education System}

The world becomes increasingly interconnected, so do the risks we face. The COVID-19 pandemic has not stopped at national borders. It has affected people regardless of nationality, level of education, income, which have hit the most vulnerable hardest. ${ }^{2}$ While the educational Institutions have made intensive efforts to maintain learning permanency during this period, children and students have had to rely more on their own resources to continue learning remotely through the Internet and Television. Teachers also had to adapt to new pedagogical concepts and modes of delivery of teaching, for which they may not have been trained. Teachers are also in a condition to adapt the new pedagogical mode and methods of teaching in the area in which they are not trained. Particularly, there is also the problem of the remote learners or students belonging to marginalized groups, who do not have any access to learn digitally. The students lack resilience power to adapt learning on their own. Already one third of the year is over in lock down and this will lead the students to skill loss because of the learning loss. If the schools are slow to return to their prior levels of performance, then the growth losses will be consistently higher. ${ }^{3}$ Due to the pandemic and with this mode of learning, the loss of knowledge and skills are significantly are higher.

\section{Sustain Education Continuity}

According to OECD, (Organisation for Economic Cooperation and Development) the education leaders need to prepare their institutions for more rapid change and even greater instability. Because the educational continuity will be more challenging in the second phase of the pandemic until the vaccine is found. Secondly, the schools and the higher education institutions need to develop protocols to maintain the social distance and safety measures following the guidelines of the public health authorities. Also implementing those effectively will require a process of design which needs to be responsive to the conditions of each educational institution. Thirdly, Create an effective delivery system for remote learning. It is essential to help students to develop the skills they need to thrive and participate in tomorrow's world. Reimagining the education delivery system requires to rethink roles. Fourthly, Sustain and deepen the teacher professional development. Finally, the reopening of institution should not be understood as merely resuming the operation of schools, but to creatively integrate the spaces, time, people and technologies into an ecosystem of learning.
The academic institutions need to assess where students are academically, and what their emotional needs are. The instructional priorities for the coming year must respond to the needs of students and to the different conditions in which it will be necessary to teach, in the modified school environments that health guidelines will create, and at home and the expanded learning ecosystem that will be essential to sustain education.

\section{Curriculum Transformation}

The Internet is now playing a bigger role in our lives and dictating how we should live, socialize, teach, and learn. As the Internet is developing into a main educational tool, online education offers the educator and the learner access to numerous resources. ${ }^{4}$ Online lectures based on a wide range of information technology equipment has raised serious challenges. Teachers who used to teach live classes will need to engage in novel methods to achieve effective teaching outcomes, which may affect the quality of tertiary education. Besides, students in remote and rural areas may not have the network capacity, thereby leading to a loss in educational opportunities. ${ }^{5}$ According to Mohmmed, Transformation process model circular shape will permit the students to obtain the information and penetrate the cycle from any point without missing the information. Through the online lectures, detailed explanation about the subject is given and the students will get the opportunities to raise their doubts about the relevant issues to the topic or overall module. Meantime, these online lectures are recorded and shared to the students on the college platform (Google Meet, MOOCS) and on the social media (MS Kaizala).

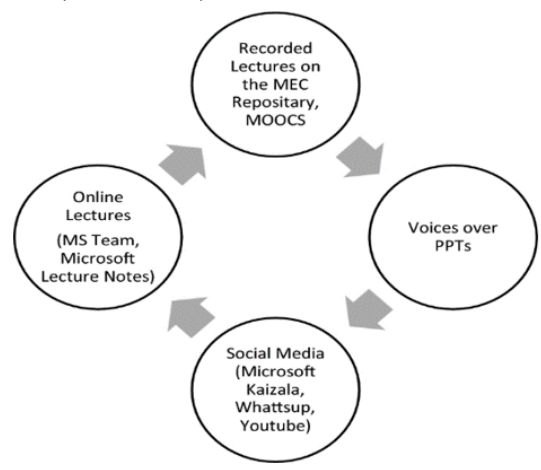

4. Course Management System

Online teaching offers exciting opportunities to expand the 
learning environment for diverse student populations. Online teaching shares much with face-to-face teaching, but it also has a unique set of skills and requirements. Both approaches are similar in content, except in pace and conveyance. For this, the Professors need to use Course Management System (CMS) software to prepare and deliver their courses. To expect good result and good response from the students and the learners, the educators must follow few recommendations and thus encouraging the students' participation and cooperation and encouraging them in to active learning and allowing them to give prompt feedback. ${ }^{6}$ The professors must encourage them to focus on cognitive engagement with material rather than on simply completing the task. There can also be a high educational standard proposed for all students in a class. Along with these principles we can add a little more. We must design more than one method of learning for the students. We should also recognize, respect, and reward creativity of the students and being sensitive to the cultural and economic differences. ${ }^{7}$ Allow the students to choose from different modes of project presentation. There is also a need to understand and allow for different pacing among the students. The professors must design course materials, activities and assessments in order to encourage analysis, synthesis, application and evaluation. ${ }^{8}$

\section{Digital Technology in Professional Teaching and Learning}

The lockdown has accelerated adoption of digital technology. It has provided a chance to develop new and improved professional skills/knowledge through online learning in more efficient and productive way. The teacher with the students outside of the classroom are using the digital tools for delivering their lectures. Thus, the online learning and digital tools are enabling us to have the continuity in leaning without a break. Here below we list out some of the digital portals that serve effectively the online learning for various fields in this pandemic.

Bharat Skills, and eSkillIndia portals are a repository of skillbased courses, where most of them follow the NSQF curriculum. Currently, the Bharat skills portal has e-learning videos available for 79 trades like carpenter, electrician, plumber, etc.Website:https://bharatskills.gov.in/

eSkillIndia, a multilingual portal offers more than 400 courses in about 10 regional languages. Content on these portals is aggregated by various knowledge and content partners.Website:https://eskillindia.org/

NASSCOM Future skills portal is a portal where students can learn the skills of the future. It is an industry-driven learning ecosystem that aims to reskill two million professionals and potential employees and students in the industry over a period of five years.Website:http://futureskills.nasscom.in/

Skillsbuild - With ever-evolving technology, new job roles are emerging daily. This requires newer skills to perform a task and make a difference in the world of work. Portal like Skillsbuild build provides courses in the latest technology like Artificial intelligence, Cybersecurity, Client engagement, etc. along with training in soft skills. Website: http://skillsbuild.org/

TCS ion Digital Learning Hub is a digital portal that offers a number of courses spread across various fields. It collaborates with several organisations to offer these courses. A couple of recent collaborations were with NSDC and NCS, to enable virtual training and job information for those in the skilling ecosystem.Website :https://www.tcsion.com/LX/log in\#lx

Swayam portal runs on the principle of access, equity, and quality. It has courses from class nine to post-graduation.
Courses delivered through SWAYAM are available free of cost to the learners. However, learners wanting a SWAYAM certificate will have to attend an exam at a fee. Eligibility for the certificate will be announced on the course page and learners will get certificates only if this criterion is matched. Website:https://swayam.gov.in/

NPTEL portal is coordinated majorly by IIT Madras along with other IITs. The portal has recorded lectures from IITs, which are then uploaded online for others to access. NPTEL has web and video courses across 23 disciplines, where learners get a tangible end result in the form of a certificate from the IITs/IISc for their effort.Website:https://nptel.ac.in/

Swayam Prabha has 32 DTH TV channels transmitting educational contents on $24 \times 7$ basis. These channels are available for viewing all across the country using DD Free Dish Set Top Box and Antenna. The channel schedule and other details are available in the portal. The channels cover both school education (classes 9 to 12) and higher education (undergraduate, postgraduate, engineering Out-of-school children, vocational courses and teacher training) in arts, science, commerce, performing arts, social sciences and humanities subjects, engineering, technology, law, medicine, agriculture. Website:https://www.swayamprabha.gov.in/.

E-patashala is an e-Learning app by NCERT for classes 1 to 12 in multiple languages. The app houses books, videos, audio, etc. aimed at students, educators and parents in multiple languages including Hindi, Urdu, and English. In this web portal NCERT has deployed 1886 audios, 2000 videos, 696 e-Books and 504 Flip Books for classes 1 to 12 in different languages. Mobile Apps is available. Website: https:// epathshala.nic.in/index.php?ln=en.

\section{Advantages of Online Learning}

Though the outbreak of COVID-19 has created many negative impacts on education, educational institutions of India have accepted the challenges and are trying their best to provide seamless support services to the students during this pandemic.

Educational institutions moved towards blended mode of learning. It has encouraged all teachers and students to become more technology savvy. The use of learning management systems by educational institutions has become a great demand. There is a new opportunity where collaborative teaching and learning can take on new forms. The COVID -19 pandemic has created a massive rise in teleconferencing, virtual meetings, webinars and econferencing opportunities. The digital source has become a high source for the students and the learners to continue the education without any break. There are improved electronic media for sharing information and educators and learners are getting better opportunities to interact with the peers from around the world. Students and the teachers are able to manage their time more efficiently. Good number of students approach different online platforms to choose their distance learning courses.

\section{Disadvantages of Online Learning}

Educational institutions have suffered a lot due to the long outbreak of the pandemic Covid-19.This situation has bought many disadvantages to the Learners, Teachers, Parents and the society. Due to this COVID-19, all the educational system became vulnerable. Classes have been suspended and exams are postponed. Admission of the year process got delayed and placements for students was affected with companies delaying the on board of students. Most of the teachers are just conducting lectures on video platforms such as Zoom, Google meet etc., which may not be a real online learning without any dedicated online learning platform. Some of those from other countries have lose their jobs and 
students who have passed out of the educational institutions could not get their job outside India due to the restrictions caused by COVID-19. ${ }^{9}$ Many students who have already got jobs through campus interviews could not join their jobs due to lockdown. Some educated parents are able to guide and teach their children but many parents may not have the adequate level of education needed to teach their children in the house. As many students have limited or no internet access and as many students cannot afford a computer, laptop or supporting mobile phones in their homes, the online teaching-learning has created a digital divide among students. During this lockdown many of the parents have faced the unemployment situation which did not allow them to pay the fee within the particular time periods. This has definitely affected the private educational institutes.

\section{CONCLUSION}

The COVID-19 has an immense impact on the education sector of India. It has indeed created many challenges. Students and the teachers constantly face the difficulty of adapting to new digital learning platform. Due to this pandemic, the concept of work from home has gained greater relevance to reduce the spread of COVID-19. In the same manner, the government can draw policies for the enhancement of digital learning for the students who are unable to make a choice of the digital platforms that are available. In the present condition of the pandemic, for the effective delivery of education in a digital platform and to enable the students to complete their degrees, the various government policies must include students from diverse backgrounds, those from the remote regions, and those from the marginalised and the minority groups. As the online practice is giving lots of benefits to the students, the educational spectrum can continue even after the lockdown.

\section{REFERENCES}

1. Transformation Of Higher Education; How COVID- 19 Is Changing The Face Of Education http://bweducation.businessworld.in/article/TransformationOf-Higher-Education-How-COVID-19-Is-Changing-The-Face-OfEducation/08-07-2020-295372/ (accessed on 12 November 2020).

2. Andreas Schleicher, "The Impact of Covid-19 On Education - Insights from Education at a Glance' 2020, OECD 2020. https://www.oecd.org/ education/the-impact-of-covid-19-on-education-insights-education-at-aglance. (accessed on 7 November 2020).

3. Schleicher, A. and F. Reimers (2020), Schooling Disrupted, Schooling Rethought: How the COVID-19 Pandemic is Changing Education, OECD, https://read.oecd-ilibrary.org/view/?ref=133_133390- lrtuknc0hi\&title= Schooling-disr uptedschooling-Rethought-How-the-Covid-19-pandemic-ischanging-education (accessed on7 October 2020).

4. Matthew N. O. Online Teaching and Learning, International Journals of Advanced Research in Computer Science and Software Engineering ISSN: 2277-128X (Volume-8, Issue-2)

5. Abdalellah O. Mohmmed, Basim A. Khidhir, Abdul Nazeer, Vigil J. Vijayan, Emergency remote teaching during Coronavirus pandemic: the current trend and future directive at Middle East College Oman, Springer Nature Switzerland, Published online: 1 July 2020.

6. MHRD notice (20 March, 2020). COVID-19 Stay Safe: Digital Initiatives. Retrieved on May 25, 2020 from https://www.mohfw.gov.in/pdf/Covid 19.pdf

7. Kremer, John F. "Students Offered Choice of Type of Computer Exercise for Assignments". The Trustees of Indiana University, Copyright 1999-2003. http://attf.iu.edu/about/goodpract/kremer.html

8. Colorado State University, "Respect Diverse Talents and Ways of Learning". Copyright 2006-2008.

http://tilt.colostate.edu/coursedev/best_practices/best_practices8.cfm accessed on 8 November 2020 .

9. Study Abroad Life (2020). How Covid-19 will affect the Indian education system. Retrieved on May 25, 2020 from https://www.study abroad life.org/how-covid-19-will-affect-the-indian-education-system/ 